\title{
Virtual prediction of purple rice ferulic acid as anti-inflammatory of TNF- $\alpha$ signaling
}

\author{
Ernanin Dyah Wijayanti ${ }^{1,2,3}$, Anna Safitri ${ }^{2,4}$, Dian Siswanto ${ }^{1}$, and Fatchiyah Fatchiyah ${ }^{1,2^{*}}$ \\ ${ }^{1}$ Department of Biology, Faculty of Mathematics and Natural Sciences, Brawijaya University \\ ${ }^{2}$ Research Center of Smart Molecule of Natural Genetics Resources, Brawijaya University \\ ${ }^{3}$ Academy of Pharmacy of Putra Indonesia Malang \\ ${ }^{4}$ Department of Chemistry, Faculty of Mathematics and Natural Sciences, Brawijaya University
}

Abstract

Purple rice is one of the main sources of ferulic acid (FA). Some studies reported anti-inflammatory properties of FA, but the interaction of FA with TNF- $\alpha$ signaling has not been elucidated. TNF- $\alpha$ is a target for anti-inflammatory drug research due to its major role in the inflammatory process. This study aims to investigate the interaction of FA with TNF- $\alpha$ and TNF- $\alpha$ receptor (TNFR) through in silico study and evaluate the drug-like properties and biological activity of FA. The interactions among FA (CID 445858), TNF- $\alpha$ (2AZ5), and TNFR (1NCF) were docked by Hex 8.0.0 Cuda, then visualized by Discovery Studio 2020 and LigPlot V.1.4.5. Apigenin-7-glucuronide (AG, CID 5319484) was used as the positive control. The drug-like properties were predicted by Lipinski's rule of five and the biological activity was analyzed by PASS online. FA showed good properties as a drug-like molecule and biological activity as an anti-inflammatory. FA also showed good interaction with TNF- $\alpha$ and TNFR. FA bound to TNF- $\alpha$ at Asn92(B), Val91(B), Leu93(B), Phe124(B), Phe124(D), and Leu93(D) residues with docking energy of $-214.6 \mathrm{~kJ} / \mathrm{mol}$, and bound to TNFR at Pro16(A), Glu56(B), Cys55(B), Glu54(B) residues with docking energy of $-191.1 \mathrm{~kJ} / \mathrm{mol}$. FA could inhibit TNF- $\alpha$ - TNFR interaction by binding to TNFR at Glu54 residue, the same inhibition mechanism to AG which bind to TNFR at Glu54 and Val90. The current study shows that FA has the potential as an anti-inflammatory of TNF- $\alpha$ signaling and can be developed as an oral anti-inflammatory drug candidate.

Keywords: anti-inflammatory, ferulic acid, purple rice, TNF- $\alpha$

Received: October 22, 2021 Revised: December 16, 2021, December 18, 2021

\section{Introduction}

Ferulic acid (FA) is a derivative of phenolic compounds that are abundant in plants (Kumar \& Pruthi, 2014). FA is found in seeds, grasses, vegetables, flowers, fruits, and leaves. Some sources of ferulic acid including rice, wheat, oats, pineapple, nuts, coffee beans, artichokes, bananas, spinach, corn, rye, barley, eggplant, and beetroot (Boz, 2015; de Paiva et al., 2013; Kumar \& Pruthi, 2014). The main source of FA is rice (Alam, 2019). Among the variant color of rice, purple rice show higher content of FA $(64.58 \pm 0.40$ to $218.39 \pm 1.28 \mu \mathrm{g} / \mathrm{g})$ than black $(26.09 \pm 0.11$ to $215.21 \pm 0.21 \mu \mathrm{g} / \mathrm{g})$ and white rice $(119.37 \pm 1.81$ to $199.23 \pm 0.70 \mu \mathrm{g} / \mathrm{g})$ (Zhang et al., 2015).

Several studies reported anti-inflammatory activity of FA, such as reducing the activity of xanthine oxidase and cyclooxygenase (COX) (Zduńska et al., 2018). FA reduces the levels of inflammatory mediators by inhibiting COX, inducible nitric oxide synthase (i-NOS), and caspase-1 function, for example by activating nuclear factor kappa-B $(\mathrm{NF}-\kappa \mathrm{B})$. Another mechanism is by reducing the levels of tumor necrosis factor-alpha (TNF- $\alpha$ ) and some interleukin (IL) including IL-1 $\beta$, IL-6, IL-8. FA is also able to increase the secretion of IL-10

* Corresponding Author:

Fatchiyah Fatchiyah

Department of Biology, Faculty of Mathematics and Natural Sciences, Brawijaya University. Research Center of Smart Molecule of Natural Genetics Resources, Brawijaya University Phone: 0341-575841 Fax: 0341-575841

E-mail: fatchiya@ub.ac.id which acts as an anti-inflammatory (Ge et al., 2017; Silva \& Batista, 2017; Yin et al., 2019; Zhang et al., 2018; Zhu et al., 2014).

Among proinflammatory cytokines, TNF- $\alpha$ is the major regulator of inflammatory cytokine production that plays a pivotal part in activating inflammatory cells and the development of many chronic inflammatory diseases (Parameswaran \& Patial, 2010). Diseases associated with TNF- $\alpha$ signaling aberration including rheumatoid arthritis, Crohn's disease, atherosclerosis, ankylosing spondylitis, inflammatory bowel disease, psoriasis, sepsis, diabetes, obesity, and noninfectious uveitis (Bradley, 2008; Jang et al., 2021; Parameswaran \& Patial, 2010).

TNF- $\alpha$ is generated mainly by monocytes or macrophages. It can be produced in smaller quantities by other cells such as B and $\mathrm{T}$ lymphocytes, fibroblasts, mast cells, neutrophils, natural killer cells, and osteoclasts (Holbrook et al., 2019). TNF- $\alpha$ signals through TNF- $\alpha$ receptor (TNFR). It binds to the receptor with high affinity then transports molecular signals for inflammation and cell death (Jang et al., 2021; Parameswaran \& Patial, 2010; Wajant \& Siegmund, 2019).

The inhibition of TNF- $\alpha$ signaling can be virtually predicted by in silico study (O'Connell et al., 2019; Wang et al., 2019). Molecular docking can be used to analyze the binding mode of a compound in a drug discovery process (Xu et al., 2018). It is the most commonly used method with low cost and fast results to characterize the binding site of protein-ligand (Kim et al., 
2016). The docking method could be validated by using reference ligand (Parikesit \& Nurdiansyah, 2021), such as apigenin-7-glucuronide (AG) as the TNF-inhibitor (Salehi et al., 2019).

As TNF- $\alpha$ is crucial in the inflammatory process, the inhibition of TNF- $\alpha$ signaling is a recent target for drug research (Bai et al., 2021). The ability of FA in preventing TNF- $\alpha$ signaling will explain a new mechanism of FA as an anti-inflammatory agent. Therefore, this study aims to investigate the interaction of FA with TNF- $\alpha$ and TNFR by in silico study and evaluate the drug-like properties and biological activity of FA.

\section{Method}

\section{Protein and ligand preparation}

Ferulic acid of purple rice was retrieved from the Pubchem Compound database from NCBI with Pubchem CID 445858

(https://pubchem.ncbi.nlm.nih.gov/compound/445858).

AG was used as reference, also retrieved from Pubchem with CID

5319484 (https://pubchem.ncbi.nlm.nih.gov/compound/5319484). FA and AG structures were converted to PDB format using PyRx software (Hikmawati et al., 2020). While the three-dimensional protein structures were obtained from the RCSB PDB including TNF- $\alpha$ (2AZ5, https://www.rcsb.org/structure/2AZ5) and TNFR (1NCF, https://www.rcsb.org/structure/1NCF). The water molecules and ligand bound to protein structures were eliminated by Discovery Studio 2020 software (Tapiory et al., 2020). All of the softwares were used by default setting.

\section{Prediction of drug-likeness and biological activity}

The drug-like properties of FA were predicted by running the Lipinski's rule of five server (http://scfbioiitd.res.in/software/drugdesign/lipinski.jsp). The pdb form of FA was submitted to the server to generate data including molecular mass, number of hydrogen bond donor and acceptor, $\log \mathrm{P}$ value, and molar refractivity (Sreelakshmi et al., 2017).

The biological activity was predicted by PASS online (http://www.way2drug.com/passonline/predict.php) by submitting the canonical SMILES of FA to get the prediction of the biological activity of FA (Basha et al., 2018; Sari et al., 2019). We screened for the biological activity related to anti-inflammatory with $\mathrm{Pa}$ value $\geq 0.3$. All of the servers were used by default setting.

\section{Molecular docking and visualization}

The molecular docking among FA, TNF- $\alpha$, and TNFR were designed as follow: (1) TNF- $\alpha$ and TNFR, (2) TNF- $\alpha$ - TNFR complex and FA, (3) TNF- $\alpha$ and FA, (4) TNF- $\alpha$ - FA complex and TNFR, (5) TNFR and FA, (6) TNFR - FA complex and TNF- $\alpha$. The docking were carried out using the blind docking Hex 8.0.0 Cuda with Shape+Electro+DARS, root-mean-square deviation (RMSD) value $\leq 2 \AA$, and other parameter as default. The docking validation method was performed with AG as the positive control. The interaction was visualized by Discovery Studio 2020 software and LigPlot V.1.4.5 to analyze the binding sites (Faizah et al., 2021; Safitri et al., 2021). The Discovery Studio 2020 and LigPlot V.1.4.5 were used by default setting.

\section{Results}

The drug-like properties and biological activity of FA

The drug-like properties and biological activity of FA were performed in Tables 1 and 2. FA has a molecular mass $<500$ Dalton, $\log \mathrm{P}<5$, hydrogen $(\mathrm{H})$ bond acceptors $<10, \mathrm{H}$ bond donors $<5$, and molar refractivity between $40-130$. There is no violation of Lipinski's rule of five, thus FA meets the criteria as a drug-like molecule.

The prediction of the biological activity of FA was performed to validate the suitability of FA as an antiinflammatory of TNF- $\alpha$ signaling. FA exhibits some biological activities related to anti-inflammatory, including TNF expression inhibitor; anti-inflammatory in general, intestinal, and ophthalmic; and non-steroidal anti-inflammatory agent. Those activities have $\mathrm{Pa}$ more than the $\mathrm{Pi}$ value and the $\mathrm{Pa}$ value $\geq 0.3$. The biological activity as a TNF expression inhibitor showed the highest $\mathrm{Pa}$ value $(>0.7)$, while the others range between $0.3-0.7$. Regarding the biological activity, FA is suitable as the ligand of the docking.

Table 1. The Lipinski's properties of FA

\begin{tabular}{lc}
\multicolumn{1}{c}{ Property } & Value \\
\hline Molecular mass & $194 \mathrm{Da}$ \\
LogP & 1.499 \\
H bond donor & 2 \\
H bond acceptors & 4 \\
Molar refractivity & 51.329 \\
\hline
\end{tabular}

Table 2. The predicted biological activity of FA

\begin{tabular}{lll}
\hline \multicolumn{1}{c}{ Biological activity } & $\mathrm{Pa}^{\mathrm{a}}$ & $\mathrm{Pi}^{\mathrm{b}}$ \\
\hline TNF expression inhibitor & 0.8 & 0.003 \\
\hline Anti-inflammatory, intestinal & 0.6 & 0.003 \\
\hline Anti-inflammatory & 0.6 & 0.031 \\
\hline Anti-inflammatory, ophthalmic & 0.3 & 0.011 \\
\hline Non-steroidal anti-inflammatory agent & 0.3 & 0.026 \\
\hline
\end{tabular}

a $\mathrm{Pa}$ is probability to be active

${ }^{b} \mathrm{Pi}$ is probability to be inactive

\section{The interaction of FA with TNF- $\alpha$ and TNFR}

Molecular docking has been conducted to examine the interaction among FA, TNF- $\alpha$, and TNFR. To examine how ferulic acid inhibits TNF- $\alpha$ signaling, by binding to TNF- $\alpha$ and/or TNFR, the docking was designed between TNF- $\alpha$ and TNFR, TNF- $\alpha-$ TNFR complex and FA, TNF- $\alpha$ and FA, TNF- $\alpha-$ FA complex and TNFR, TNFR and FA, and TNFR - FA complex and TNF- $\alpha$. Figure 1 and Table 3 showed that FA could interact with TNF- $\alpha$, TNFR, and also TNF- $\alpha-$ TNFR complex. FA interacts with TNF- $\alpha$ in some residues including Asn92(B), Val91(B), Leu93(B), Phe124(B), Phe124(D), and Leu93(D) with hydrophobic bonds. 

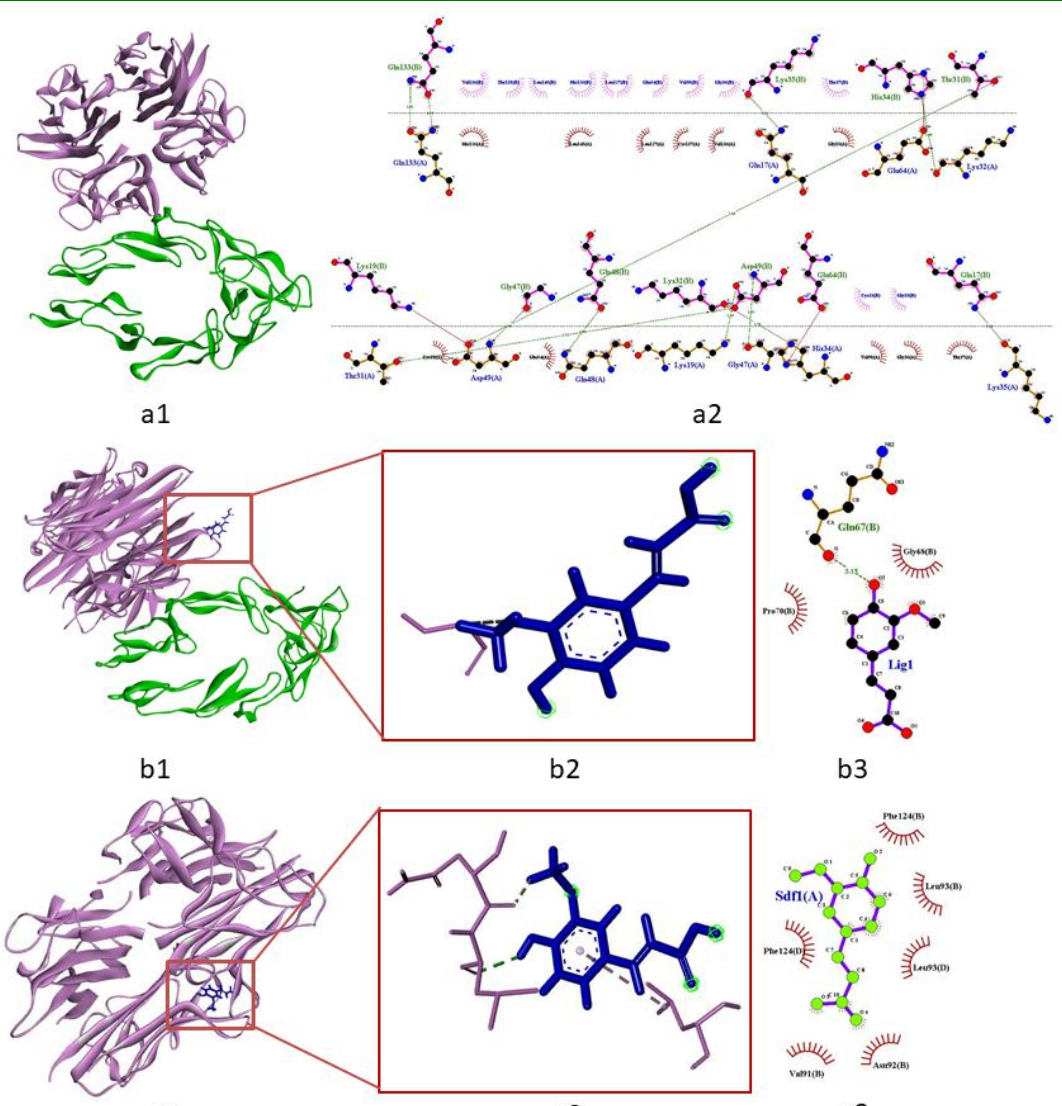

b3

c1

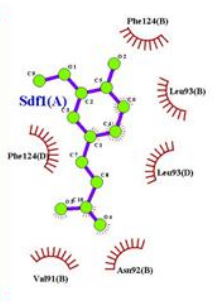

c3
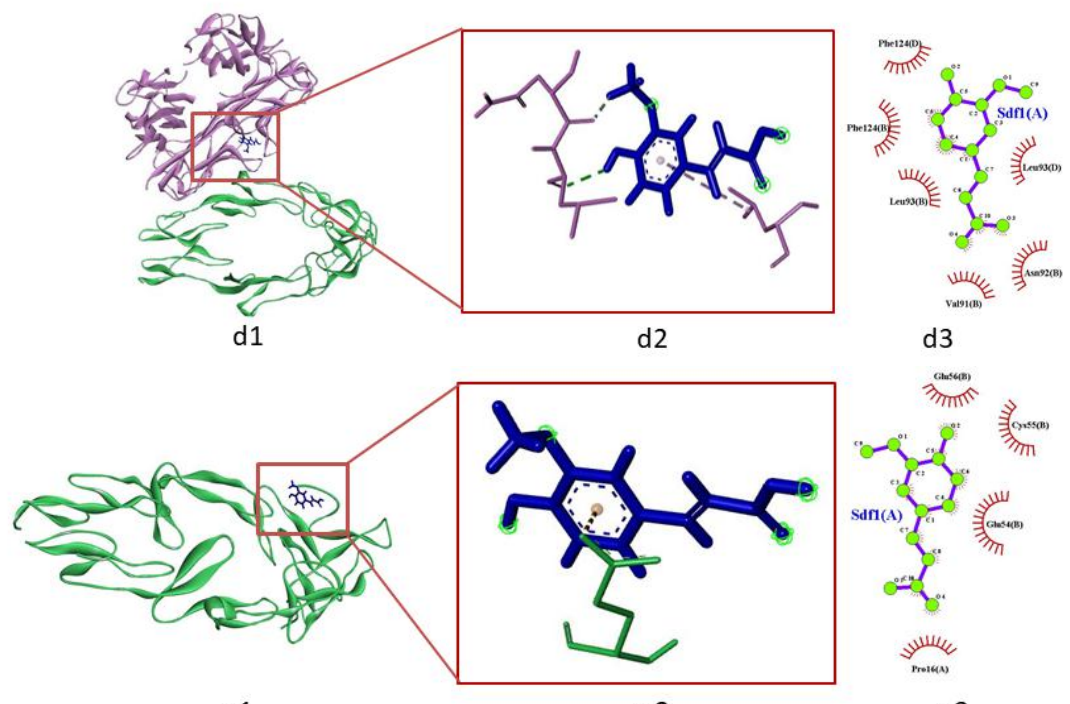

e1

e2

e3

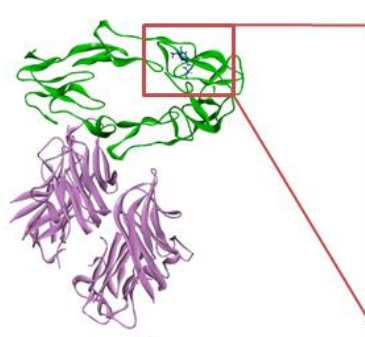

$\mathrm{f1}$

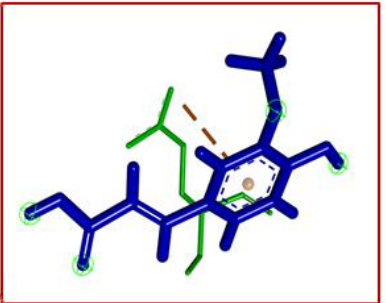

f2

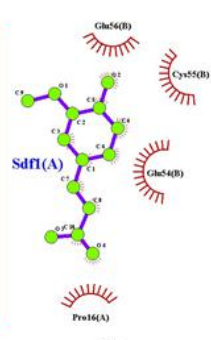

f3

Figure 1. Interaction of FA with TNF- $\alpha$ and TNFR. (a1) The conformation of TNF- $\alpha$ and TNFR interaction, (a2) 2D structure; (b1) The conformation of TNF- $\alpha$ and TNFR complex interacted with FA, (b2) 3D and (b3) 2D structures; (c1) The conformation of TNF- $\alpha$ and FA interaction, (c2) 3D and (c3) 2D structures; (d1) The conformation of TNF- $\alpha$ and FA complex interacted with TNFR, (d2) 3D and (d3) 2D structures; (e1) The conformation of TNFR and FA interaction, (e2) 3D and (e3) 2D structures; (f1) The conformation of TNFR and FA complex interacted with TNF- $\alpha$, (f2) 3D and (f3) 2D structures. FA, TNF- $\alpha$, and TNFR are colored in blue, purple, and green, respectively. 
When this complex interacts with the TNF- $\alpha$, the binding sites are the same as TNFR - FA interaction indicating that FA is still bound to TNFR. The interaction of TNFR - FA - TNF- $\alpha$ generated lower binding energy than TNFR - FA interaction. Among the residues in the binding site of FA and TNFR, Glu54(B) is also found in the interaction of TNF- $\alpha-$ TNFR.

Figure 1 also showed the interaction of FA with TNF- $\alpha$ - TNFR complex in some residues including Gln67(B) (hydrogen bond), Gly68(B), and Pro70(B) (hydrophobic bonds). This interaction produced higher binding energy than the interaction of TNF- $\alpha-$ TNFR. While TNF- $\alpha$, as the native ligand, binds to TNFR with bond type including hydrogen, hydrophobic, and interface 2 bonds.

The validation of the docking method was conducted with AG as the reference. Figure 2 and Table 4 showed the interaction of AG with TNF- $\alpha$ and TNFR in some amino acid residues. AG bind to TNF- $\alpha$ with hydrophobic bonds, and bind to TNFR with hydrophobic and hydrogen bonds. Among the residues in the binding site of AG and TNFR, Glu54(B) and Val90(B) are the residues at the binding site of TNF- $\alpha-$ TNFR.

From all of the docking simulations, we observed the stable binding of FA - TNF- $\alpha$ and FA - TNFR as well as AG - TNF- $\alpha$ and AG - TNFR. Those were indicated by the same position of FA/AG and their binding sites when those complexes interacted with TNFR/TNF- $\alpha$. All of the residues in the binding site of TNFR - FA are the same as some residues in the binding site of TNFR - AG. The Glu54(B) was found in the interaction of TNFR - FA, TNFR - AG, and TNFR - TNF- $\alpha$. It showed that FA could bind to the binding site of TNF- $\alpha$ - TNFR, then inhibit the binding between TNF- $\alpha$ and TNFR. While AG inhibits TNF- $\alpha$ - TNFR interaction by binding to TNFR at Glu54(B) and Val90(B). According to the binding energy, interaction of TNF- $\alpha$ and TNFR with FA generated higher binding energy, indicating that FA attenuated the binding of TNF- $\alpha$ and TNF.

Table 3. Interaction points, bond type, and energy of the docking among FA, TNF- $\alpha$, and TNFR

\begin{tabular}{|c|c|c|c|}
\hline Interaction & Interaction point & Bond type & Energy $(\mathrm{kJ} / \mathrm{mol})$ \\
\hline \multirow[t]{11}{*}{ a. TNF- $\alpha+$ TNFR } & Gln133(B)-Gln133(A), Lys35(B)-Gln17(A), His34(B)- & Hydrogen & -437.8 \\
\hline & Lys32(A), Thr31(B)-Asp49(A), Gly47(B)- Asp49(A), & & \\
\hline & Gln48(B)-Gln48(A), Lys32(B)-His34(A), Asp49(B)- & & \\
\hline & Lys19(A), Asp49(B)-Gly47(A), Gln17(B)-Lys35(A), & & \\
\hline & Asp49(B)-Thr31(A) & & \\
\hline & His34(B)-Glu64(A), Lys19(B)-Asp49(A), Glu64(B)- & Hydrophobic & \\
\hline & His34(A), His126(A), Leu145(A), Leu127(A), & & \\
\hline & Cys137(A), Val136(A), Gly18(A), Cys33(A), & & \\
\hline & Glu54(A), Val90(A), Gly36(A), Thr37(A) & & \\
\hline & Val136(B), Thr138(B), Leu145(B), His126(B), & Interface 2 & \\
\hline & $\begin{array}{l}\text { Leu127(B), Glu54(B), Val90(B), Gly36(B), Thr37(B), } \\
\text { Cys33(B), Gly18(B) }\end{array}$ & bonds & \\
\hline \multirow[t]{2}{*}{ b. TNF- $\alpha-$ TNFR complex + FA } & Gln67(B) & Hydrogen & -79.9 \\
\hline & Gly68(B), Pro70(B) & Hydrophobic & \\
\hline c. TNF- $\alpha+$ FA & $\begin{array}{l}\text { Asn92(B), Val91(B), Leu93(B), Phe124(B), Phe124(D), } \\
\text { Leu93(D) }\end{array}$ & Hydrophobic & -214.6 \\
\hline d. TNF- $\alpha$ - FA complex + TNFR & $\begin{array}{l}\text { Asn92(B), Val91(B), Leu93(B), Phe124(B), Phe124(D), } \\
\text { Leu93(D) }\end{array}$ & Hydrophobic & -445.9 \\
\hline e. $\mathrm{TNFR}+\mathrm{FA}$ & Pro16(A), Glu56(B), Cys55(B), Glu54(B) & Hydrophobic & -191.1 \\
\hline f. TNFR - FA complex + TNF- $\alpha$ & Pro16(A), Glu56(B), Cys55(B), Glu54(B) & Hydrophobic & -445.2 \\
\hline
\end{tabular}



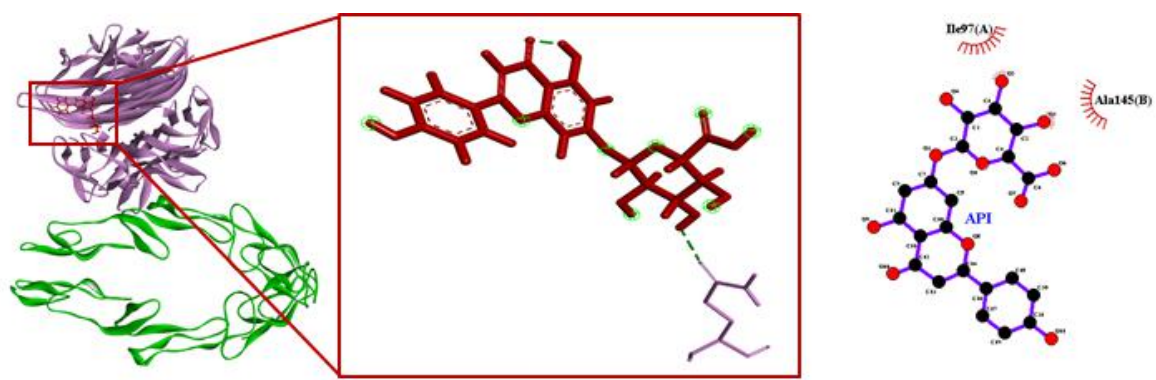

a1

a2

a3
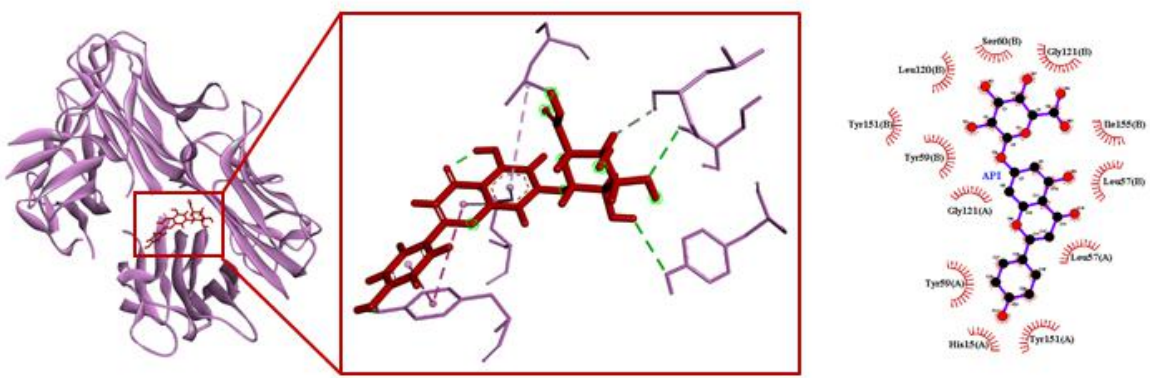

b1

b2

b3
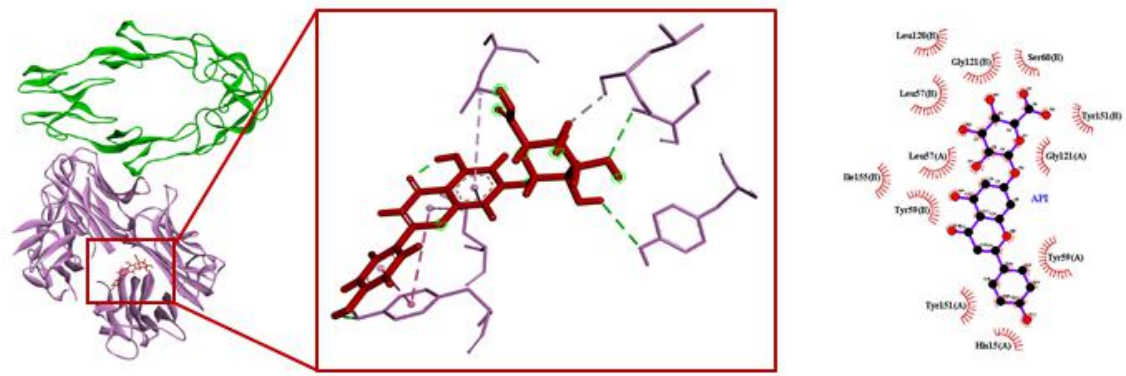

c1

c2

c3
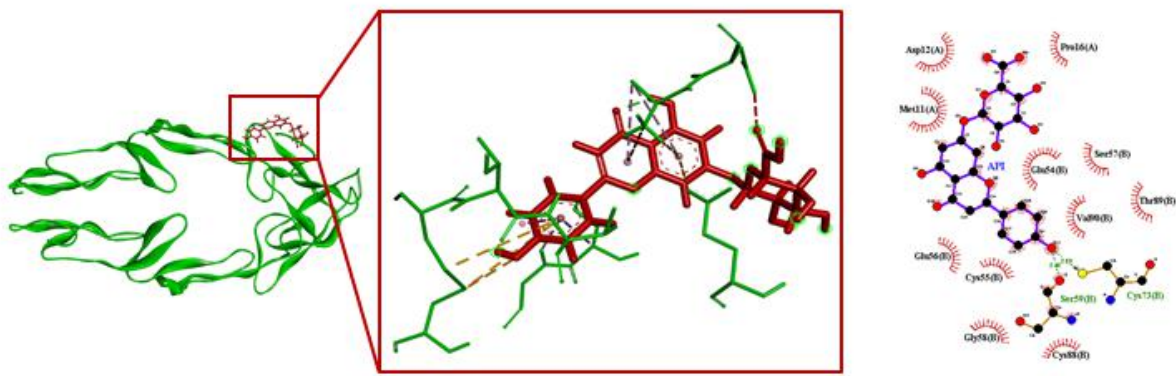

d1

d2

d3

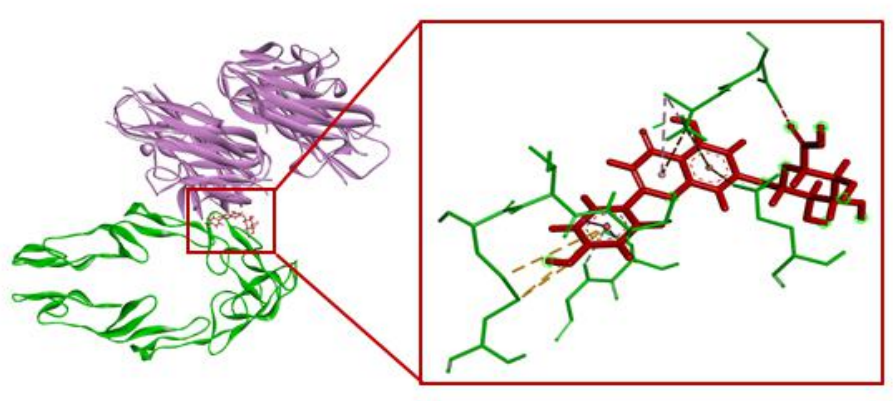

e1

e2

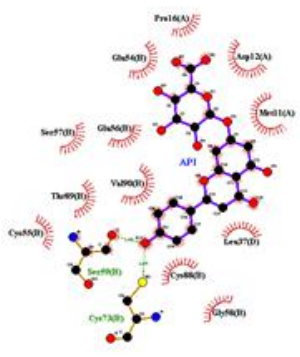

e3

Figure 2. Interaction of AG with TNF- $\alpha$ and TNFR. (a1) The conformation of TNF- $\alpha$ and TNFR complex interacted with AG, (a2) 3D and (a3) 2D structures; (b1) The conformation of TNF- $\alpha$ and AG interaction, (b2) 3D and (b3) 2D structures; (c1) The conformation of TNF- $\alpha$ and AG complex interacted with TNFR, (c2) 3D and (c3) 2D structures; (d1) The conformation of TNFR and AG interaction, (d2) 3D and (d3) 2D structures; (e1) The conformation of TNFR and AG complex interacted with TNF- $\alpha$, (e2) 3D and (e3) 2D structures. AG, TNF- $\alpha$, and TNFR are colored in red, purple, and green, respectively. 
Table 4. Interaction points, bond type, and energy of the docking among AG, TNF- $\alpha$, and TNFR

\begin{tabular}{|c|c|c|c|}
\hline Interaction & Interaction point & Bond type & Energy (kJ/mol) \\
\hline a. TNF- $\alpha-$ TNFR complex + AG & Ile97(A), Ala145(B) & Hydrophobic & -141.9 \\
\hline b. TNF- $\alpha+$ AG & $\begin{array}{l}\text { Leu57(A), Tyr151(A), His15(A), Tyr59(A), Gly121(A), } \\
\text { Leu120(B), Gly121(B), Ser60(B), Ile155(B), Leu57(B), } \\
\text { Tyr59(B), Tyr151(B) }\end{array}$ & Hydrophobic & -325.4 \\
\hline c. TNF- $\alpha$ - AG complex + TNFR & $\begin{array}{l}\text { Leu57(A), Tyr151(A), His15(A), Tyr59(A), Gly121(A), } \\
\text { Leu120(B), Gly121(B), Ser60(B), Ile155(B), Leu57(B), } \\
\text { Tyr59(B), Tyr151(B) }\end{array}$ & Hydrophobic & -443.0 \\
\hline \multirow[t]{2}{*}{ d. $\mathrm{TNFR}+\mathrm{AG}$} & $\begin{array}{l}\text { Pro16(A), Asp12(A), Met11(A), Cys88(B), Gly58(B), } \\
\text { Cys55(B), Thr89(B), Va190(B), Ser57(B), Glu56(B), } \\
\text { Glu54(B) }\end{array}$ & Hydrophobic & -287.3 \\
\hline & Ser59(B), Cys73(B) & Hydrogen & \\
\hline \multirow[t]{2}{*}{ e. TNFR - AG complex + TNF- $\alpha$} & $\begin{array}{l}\text { Pro16(A), Asp12(A), Met11(A), Cys88(B), Gly58(B), } \\
\text { Cys55(B), Thr89(B), Va190(B), Ser57(B), Glu56(B), } \\
\text { Glu54(B), Leu37(D), }\end{array}$ & Hydrophobic & -464.1 \\
\hline & Ser59(B), Cys73(B) & Hydrogen & \\
\hline
\end{tabular}

\section{Discussion}

Ferulic acid belongs to phenolic acid, which has many physiological functions including antioxidant and anti-inflammatory (Zduńska et al., 2018). The antiinflammatory activity of FA on TNF- $\alpha$ signaling has not been explained. The interactions of FA with TNF- $\alpha$ and TNFR were predicted by molecular docking. The druglike properties and biological activity of FA were also presented. AG was used as the reference ligand to validate the docking method, as it was considered as the inhibitor of TNF- $\alpha$ (Palmieri et al., 2012). Ligand-protein interaction analysis can be used to understand the indepth molecular interactions of the active site and the binding mechanism (Xu et al., 2018). The docking was performed using Hex soft due to the advantage of spherical polar Fourier correlations to advance the docking and superposition calculations. The calculations are natural and seamless way, using 3D parametric functions to program surface shape, electrostatic charge, and potential distributions (Bagali \& Gowrishankar, 2016).

The drug-like properties of FA was predicted by Lipinski's rule of 5, which differentiate drug-like and non drug-like molecule. It states that drug-like molecules should have a molecular mass $<500$ Dalton, $\log \mathrm{P}<5$, hydrogen $(\mathrm{H})$ bond acceptors $<10, \mathrm{H}$ bond donors $<5$, and molar refractivity between 40-130 (Lipinski, 2004). Lipinski's rule of five correlated with oral bioavailability or membrane permeability of compound thus it is used as drug-likeness prediction (Kadam \& Roy, 2007). The molecular mass below 500 indicated that the compound can be transported, diffused, and absorbed easily. The value of $\operatorname{LogP}$ less than 5 expressed high lipophilicity, indicating high permeability to cells (Hikmawati et al., 2020; Lipinski, 2004). The number of hydrogen bond donors and acceptors are related to the rate of drug diffusion, while molar refractivity is related to steric/hydrophobic feature (Damião et al., 2014). The orally active drugs should have no violation of Lipinski's rule of five (Khan et al., 2017). The present study showed that FA qualifies as a drug-like molecule due to complying with Lipinski's rule of five.

According to the prediction of biological activity by PASS analysis, FA exhibits some anti-inflammatory activities with $\mathrm{Pa}$ more than Pi value. PASS analysis has been used broadly to confirm and correlate biological activities of compounds, which are based on the structure-activity relationship with a known chemical (Jamkhande et al., 2016). Based on leave one out crossvalidation (LOOCV), PASS analysis has an average prediction accuracy of $95 \%$ (Basha et al., 2018). The prediction was based on $\mathrm{Pa}$ and $\mathrm{Pi}$ values. The range of $\mathrm{Pa}$ and $\mathrm{Pi}$ values is 0.000-1.000 (Kurashov et al., 2016). If a compound has $\mathrm{Pa}$ more than $\mathrm{Pi}$ value, then it is suggested to be active (Filimonov et al., 2020). If the Pa value is higher, then the probability of a false-positive result in biological testing is lower (Basanagouda et al., 2011). The $\mathrm{Pa}$ value between $0.3-0.7$ is considered to have moderate activity, while $>0.7$ is high activity (Parikesit \& Nurdiansyah, 2021). Regarding the Pa value, FA showed high activity as a TNF expression inhibitor and moderate activities as an anti-inflammatory in general, intestinal, and ophthalmic, and also nonsteroidal anti-inflammatory agent.

There are some amino acid residues involved in the interaction of FA with TNF- $\alpha$ and TNFR. The residues of TNF- $\alpha$ were Asn92(B), Val91(B), Leu93(B), Phe124(B), Phe124(D), and Leu93(D) These residues were different from the binding sites of TNF- $\alpha$ with other compounds. The binding sites of anthocyanins to TNF- $\alpha$ were Ser60, Leu57, and Tyr59 (Sari et al., 2019). 
Curcumin diglucoside bind to TNF- $\alpha$ at Asn39, Lys11, Ala156, and Gly121, curcumin monoglucoside at His15, Leu36, and Gly121, and sophoricoside at Tyr59, Tyr151, Gln61, Ser60, and Leu120 (Xu et al., 2018). While triterpene saponins bind at Gln102, Arg103, Glu104, Thr105, Glu107, Cys69, Pro100, Cys101, Ala109, Pro113, and Trp114 residues of TNF- $\alpha$ (Kim et al., 2016). The residues involved in the interaction of FA with TNFR include Pro16(A), Glu56(B), Cys55(B), and Glu54(B). Glu54 is also the residue at the binding site of AG with TNFR and involved in the interaction of TNF- $\alpha$ - TNFR. Similar to the previous study, the Glu54 and Glu56 residues are the binding sites of the peonidin-3-Oglucoside and TNFR. The peonidin-3-O-glucoside inhibited TNF- $\alpha$ signaling by binding to TNFR (Sari et al., 2019). This mechanism is the same with FA, which inhibits TNF- $\alpha$ - TNFR interaction by binding to TNFR. The inhibition of TNF- $\alpha-$ TNFR interaction also showed by the different positions of TNF- $\alpha$ and TNFR between the conformational structure of TNFR - FA - TNF- $\alpha$ and TNF- $\alpha-$ TNFR complexes.

The binding energy resulting from the interaction of TNF- $\alpha-$ TNFR with FA is higher than the only TNF- $\alpha-$ TNFR complex. It showed that FA could reduce the binding between TNF- $\alpha$ and TNFR. The lower the binding energy, the greater the binding efficiency, and the greater the hydrogen bond between enzyme and ligand, determines the binding strength (Biswal et al., 2019).

Inapropriate activation of $\mathrm{TNF}-\alpha$ signaling leads to chronic inflammation and the development of pathological complications (Jang et al., 2021). By inhibiting TNF- $\alpha$ signaling, FA might prevent excessive activation of inflammatory cells and the development of the related disease. The ability of FA to inhibit TNF- $\alpha$ signaling is in accordance with the prediction of biological activity of FA as an anti-inflammatory. FA could be developed as an orally active anti-inflammatory agent candidate.

This study showed that FA succeed to prevent TNF- $\alpha$ interact to its receptor properly. This prevention indicated that FA has a potential biological activity as an anti-inflammatory on TNF- $\alpha$ signaling.

\section{Acknowledgement}

This study was supported by Indonesia Endowment Fund for Education/LPDP, Ministry of Finance, Republic of Indonesia, and partly supported by RISPROPRN-LPDP-PAJALE research grant. Authors thanked to Dewi Ratih TS, Zyana Fithri NF, and SMONAGENES members for helping to finish this research.

\section{References}

Alam M.A. (2019). Anti-hypertensive effect of cereal antioxidant ferulic acid and its mechanism of action. Frontiers in Nutrition, 6: $1-7$.

Bagali S.S., \& Gowrishankar B.S. (2016). Molecular docking of antipain inhibitor using Hex software. International Journal of Computational Biology and Bioinformatics, 2(1): 3-8.

Bai L.L., Chen H., Zhou P., \& Yu J. (2021). Identification of tumor necrosis factor-alpha (TNF- $\alpha$ ) inhibitor in rheumatoid arthritis using network pharmacology and molecular docking. Frontiers in Pharmacology, 12: 1-12.

Basanagouda M., Jadhav V.B., Kulkarni M.V., \& Nagendra R.R (2011). Computer aided prediction of biological activity spectra: Study of correlation between predicted and observed activities for Coumarin-4-Acetic acids. Indian Journal of Pharmaceutical Sciences, 73(1): 88-92.

Basha S.A., Yunoos M., \& Ahmed J. (2018). PASS: A computerized prediction of biological activity spectra for chemical substances. Indo American Journal of Pharmaceutical Research, 8(06): 1441-1445.

Biswal R.A., Venkataraghavan R., Pazhamalai V., \& Romauld S.I. (2019). Molecular docking of various bioactive compounds from essential oil of Trachyaspermum ammi against the fungal enzyme Candidapepsin-1. Journal of Applied Pharmaceutical Science, 9(5): 21-32.

Boz H. (2015). Ferulic acid in cereals - A review. Czech Journal of Food Sciences, 33(1): 1-7.

Bradley J. (2008). TNF-mediated inflammatory disease. Journal of Pathology, 214: 149-160.

Damião M.C.F.C.B., Pasqualoto K.F.M., Polli M.C., \& Parise-Filho R. (2014). To be drug or prodrug: Structure-property exploratory approach regarding oral bioavailability. Journal of Pharmacy and Pharmaceutical Sciences, 17(4): 532-540.

de Paiva L.B., Goldbeck R., dos Santos W.D., \& Squina F.M. (2013). Ferulic acid and derivatives: Molecules with potential application in the pharmaceutical field. Brazilian Journal of Pharmaceutical Sciences, 49(3): 395-411.

Faizah Z.F.N., Kurniawan N., \& Fatchiyah F. (2021). Prediction of protein venom epitope (kistomin) from Calloselasma rhodostoma using immunoinformatics to design vaccine based on epitope. Berkala Penelitian Hayati, 27(1): 15-22.

Filimonov D.A., Rudik A.V., Dmitriev A.V., \& Poroikov V.V. (2020). Computer-aided estimation of biological activity profiles of drug-like compounds taking into account their metabolism in human body. International Journal of Molecular Sciences, 21(7492): 1-13.

Ge F., Zhu S., Liu L., Yan J., Ji Y., \& Sun Z. (2017). Antiinflammatory effects of Fagopyrum cymosum administered as a potential drug for ulcerative colitis. In Experimental and Therapeutic Medicine, 14(5): 4745-4754.

Hikmawati V.F., Alam F.M., Ainnayah J.S., \& Fatchiyah F. (2020). Virtual prediction of phenolic and glucosinolate compounds with Keap1 protein as anti-aging by stimulating Nrf2. J.Exp. Life Sci., 10(2): 104-112.

Holbrook J., Lara-Reyna S., Jarosz-Griffiths H., \& McDermott M. (2019). Tumour necrosis factor signalling in health and disease [version 1; referees: 2 approved]. F1000Research, 8: 1-12.

Jamkhande P.G., Pathan S.K., \& Wadher S.J. (2016). In silico PASS analysis and determination of antimycobacterial, antifungal, and antioxidant efficacies of maslinic acid in an extract rich in pentacyclic triterpenoids. International Journal of Mycobacteriology, 5: 417-425.

Jang D.I., Lee A.H., Shin H.Y., Song H.R., Park J.H., Kang T.B., Lee S.R., \& Yang S.H. (2021). The role of tumor necrosis factor alpha $(\mathrm{TNF}-\alpha)$ in autoimmune disease and current TNF- $\alpha$ inhibitors in therapeutics. International Journal of Molecular Sciences, 22(2719): 1-16.

Kadam R., \& Roy N. (2007). Recent trends in drug-likeness prediction: A comprehensive review of in silico methods. Indian Journal of Pharmaceutical Sciences, 69(5): 609-615.

Khan T., Dixit S., Ahmad R., Raza S., Azad I., Joshi S., \& Khan A.R. (2017). Molecular docking, PASS analysis, bioactivity score prediction, synthesis, characterization and biological activity evaluation of a functionalized 2-butanone thiosemicarbazone ligand and its complexes. Journal of Chemical Biology, 10(3): 91-104.

Kim O.T.P., Le M.D., Trinh H.X., \& Nong H.V. (2016). In silico studies for the interaction of tumor necrosis factor-alpha (TNF- $\alpha$ ) with different saponins from Vietnamese ginseng (Panax vietnamesis). Biophysics and Physicobiology, 13: 173180.

Kumar N., \& Pruthi V. (2014). Potential applications of ferulic acid from natural sources. Biotechnology Reports, 4(1): 86-93.

Kurashov E.A., Fedorova E.V., Krylova J.V., \& Mitrukova G.G. (2016). Assessment of the potential biological activity of low 
molecular weight metabolites of freshwater macrophytes with QSAR. Scientifica, 2016.

Lipinski C.A. (2004). Lead- and drug-like compounds: The rule-of-five revolution. Drug Discovery Today: Technologies, 1(4): 337341.

O’Connell J., Porter J., Kroeplien B., Norman T., Rapecki S., Davis R., McMillan D., Arakaki T., Burgin A., Fox D., Ceska T., Lecomte F., Maloney A., Vugler A., Carrington B., Cossins B.P., Bourne T., \& Lawson A. (2019). Small molecules that inhibit TNF signalling by stabilising an asymmetric form of the trimer. Nature Communications, 10: 1-12.

Palmieri D., Perego P., \& Palombo, D. (2012). Apigenin inhibits the TNF $\alpha$-induced expression of eNOS and MMP-9 via modulating Akt signalling through oestrogen receptor engagement. Molecular and Cellular Biochemistry, 371: 129136.

Parameswaran N., \& Patial S. (2010). Tumor necrosis factor- $\alpha$ signaling in macrophages. Crit Rev Eukaryot Gene Expr, 20(2) 87-103.

Parikesit A.A., \& Nurdiansyah R. (2021). Natural products repurposing of the H5N1-based lead compounds for the most fit inhibitors against 3C-like protease of SARS-CoV-2. Journal of Pharmacy and Pharmacognosy Research, 9(5): 730-745.

Safitri A., Sari D.R.T., Fatchiyah F., \& Roosdiana A. (2021). Modeling of aqueous root extract compounds of Ruellia tuberosa L. for alpha-glucosidase inhibition through in silico study. Makara Journal of Science, 25(1): 51-60.

Salehi B., Venditti A., Sharifi-Rad M., Kręgiel D., Sharifi-Rad J., Durazzo A., Lucarini M., Santini A., Souto E.B., Novellino E., Antolak H., Azzini E., Setzer W.N., \& Martins N. (2019). The therapeutic potential of apigenin. International Journal of Molecular Sciences, 20(1305): 1-26.

Sari D.R.T., Cairns J.R.K., Safitri A., \& Fatchiyah F. (2019). Virtual prediction of the delphinidin-3-o-glucoside and peonidin-3-oglucoside as anti-inflammatory of TNF- $\alpha$ signaling. Acta Informatica Medica, 27(3): 152-157.

Silva E de O., \& Batista R. (2017). Ferulic acid and naturally occurring compounds bearing a feruloyl moiety: A review on their structures, occurrence, and potential health benefits. Comprehensive Reviews in Food Science and Food Safety, 16(4): 580-616.

Sreelakshmi V., Raj N., \& Abraham A. 2017. Evaluation of the druglike properties of kaempferol, chrysophanol and emodin and their interactions with EGFR tyrosine kinase - An in silico approach. Natural Product Communications, 12(6): 915-920.

Tapiory A., Pertiwi K., Fadilla K., Reyhanditya D., \& Fatchiyah F. (2020). In-silico analysis of methoxyl pectin compounds from banana peels as HMG- CoA reductase inhibitor complexes. Journal of Smart Bioprospecting and Technology, 01(02): 4650.

Wajant H., \& Siegmund D. (2019). TNFR1 and TNFR2 in the control of the life and death balance of macrophages. Frontiers in Cell and Developmental Biology, 7: 1-14.

Wang S.Q., Shi M., Fang L., Xu S.M., Wang C., \& Yu Z.X. (2019). Design of dual inhibitors of human TNF- $\alpha$ and IL-6 with potentials for the treatment of rheumatoid arthritis. Tropical Journal of Pharmaceutical Research, 18(11): 2305-2312.

Xu S., Peng H., Wang N., \& Zhao M. (2018). Inhibition of TNF- $\alpha$ and IL-1 by compounds from selected plants for rheumatoid arthritis therapy: In vivo and in silico studies. Tropical Journal of Pharmaceutical Research, 17(2): 277-285.

Yin Z.N., Wu W.J., Sun C.Z., Liu H.F., Chen W.B., Zhan Q.P., Lei Z.G., Xin X., Ma J.J., Yao K., Min T., Zhang M.M., \& Wu H. (2019). Antioxidant and anti-inflammatory capacity of ferulic acid released from wheat bran by solid-state fermentation of Aspergillus niger. Biomedical and Environmental Sciences, 32(1): 11-21.

Zduńska K., Dana A., Kolodziejczak A., \& Rotsztejn H. (2018). Antioxidant properties of ferulic acid and its possible application. Skin Pharmacology and Physiology, 31(6): 332336.

Zhang H., Shao Y., Bao J., \& Beta T. (2015). Phenolic compounds and antioxidant properties of breeding lines between the white and black rice. Food Chemistry, 172: 630-639.

Zhang S., Wang P., Zhao P., Wang D., Zhang Y., Wang J., Chen L., Guo W., Gao H., \& Jiao Y. (2018). Pretreatment of ferulic acid attenuates inflammation and oxidative stress in a rat model of lipopolysaccharide-induced acute respiratory distress syndrome. International Journal of Immunopathology and Pharmacology, 32(16).

Zhu H., Liang Q.H., Xiong X.G., Chen J., Wu D., Wang Y., Yang B., Zhang Y., Zhang Y., \& Huang X. (2014). Anti-inflammatory effects of the bioactive compound ferulic acid contained in Oldenlandia diffusa on collagen-induced arthritis in rats. Evidence-Based Complementary and Alternative Medicine, 2014: 1-10. 